\title{
Lipopolysaccharide-stimulated responses in rat aortic endothelial cells by a systems biology approach
}

\author{
Hsiang-Wen Tseng ${ }^{1}$, Hsueh-Fen Juan ${ }^{2,3}$, Hsuan-Cheng Huang ${ }^{4}$, \\ John Yi-Chung Lin ${ }^{5}$, Supachok Sinchaikul', Tzi-Chung Lai ${ }^{1}$, \\ Chieh-Fu Chen ${ }^{1}$, Shui-Tein Chen ${ }^{6,7 *}$ and Guei-Jane Wang ${ }^{8}$ \\ ${ }^{1}$ Department and Institute of Pharmacology, National Yang-Ming University, Taipei, Taiwan \\ 2 Department of Life Science, National Taiwan University, Taipei, Taiwan \\ ${ }^{3}$ Institute of Cellular and Molecular Biology, National Taiwan University, Taipei, Taiwan \\ ${ }^{4}$ Institute of Bioinformatics, National Yang-Ming University, Taipei, Taiwan \\ ${ }^{5}$ Graduate Institute of Cell and Molecular Biology, Taipei Medical University, Taipei, Taiwan \\ ${ }^{6}$ Institute of Biological Chemistry and Genomics Research Center, Academia Sinica, Taipei, Taiwan \\ ${ }^{7}$ Institute of Biochemical Sciences, College of Life Science, National Taiwan University, Taipei, Taiwan \\ ${ }^{8}$ National Research Institute of Chinese Medicine, Taipei, Taiwan
}

The vascular endothelium plays an important role in regulating immune and inflammatory responses to resist pathogens infection. Although it has been known that lipopolysaccharide (LPS) is a critical inducer of sepsis or endotoxemia, the systematic responses of LPS-stimulation in endothelial cells (ECs) are still unclear. The present study aims to analyze the late-phase responses of LPS-induced rat aortic ECs by using systematic biology approaches, including rat cDNA microarray, 2-DE and MALDI-TOF MS/MS, and cytokine protein array. Furthermore, to improve the efficiency of analysis of the bulk systematic data of rat, we designed a set of bioinformatic tools to convert and integrate these rat data into the corresponding human genes or proteins IDs based on BioCarta, KEGG, and Gene Ontology databases. Using the systematic analysis, it was shown that LPS could promote some signaling or metabolic pathways as well as pathophysiologic phenomena of proliferation, atherogenesis, inflammation, and apoptosis through activated nuclear factor- $\mathrm{\kappa B}$ pathway in ECs. Interestingly, ECs also activated the mediators of anti-inflammation, antiapoptosis, and antioxidation to protect themselves. Moreover, the expressions of altered genes, proteins, and their involvement in the hypothetical signaling pathway can provide further understanding of inflammation associated responses in ECs.

\section{Keywords:}

Endothelial cells / Inflammation / Lipopolysaccharide / Systems biology
Received: April 20, 2006 Revised: June 16, 2006 Accepted: July 14, 2006
Correspondence: Dr. Guei-Jane Wang, National Research Institute of Chinese Medicine, Room 355, No. 155-1, Sec. 2, Li Nong St., Peitou Dist., Taipei 112, Taiwan

E-mail: jennyw@nricm.edu.tw

Fax: $+886-2-28250743$

\footnotetext{
Abbreviations: BGSSJ, Bulk Gene Search System for Java; CGAP, Cancer Genome Anatomy Project; ECs, endothelial cells; GO, gene ontology; iNOS, inducible nitric oxide synthase; LPS, lipopolysaccharide; NF- $\mathrm{KB}$, nuclear factor- $\mathrm{KB}$; NO, nitric oxide; PSA6, proteasome subunit $\alpha$ type 6; SODM, superoxide dismutase; TLR4, toll-like receptor 4; TNF- $\alpha$, tumor necrosis factor- $\alpha$; VDAC1, voltage-dependent anion-selective channel protein 1
}

\section{Introduction}

Sepsis is characterized by hypotension, multiple organ dysfunction, and systemic inflammation, occurring as a result of the systemic response to severe pathogen infection [1]. The vascular endothelium lining all blood vessels is the first cell type to be exposed to environmental stimuli or pathogens in circulation and plays a major role in the pathogen-

* Additional corresponding author: Dr. Shui-Tein Chen, E-mail: bcchen@gate.sinica.edu.tw 
esis of sepsis [2]. The exposure of endothelial cells (ECs) to lipopolysaccharide (LPS), a major cell wall constituent of Gram-negative bacteria, results in endothelial activation or injury through a transmembrane receptor known as the Toll-like receptor 4 (TLR4) [3, 4]. Signaling cascades through the TLR4 can activate the nuclear factor- $\kappa \mathrm{B}(\mathrm{NF}-\kappa \mathrm{B})$ [3] and produce various bioactive circulating molecules, such as cytokines (e.g., interleukin-1 $\beta$ [IL-1 $\beta]$, IL-6, and tumor necrosis factor- $\alpha$ [TNF- $\alpha]$ ), chemokines, and intracellular mediators such as nitric oxide (NO) generated by inducible nitric oxide synthase (iNOS) [5]. These molecules likewise participate in many synthetic and metabolic processes and modulation of immunity and inflammatory responses in organism [3-5]. Early sepsis is usually reversible, but patients in shock status suffer from high mortality [6]. Inflammation can induce tissue damage by oxidative stress during the immediate direct cytotoxic effect and subsequent redox-mediated inflammatory responses [6, 7]. Hence, identifying appropriate indicators for the early and late stages of septicemia is an important issue in clinical practice. Dysfunction or injury of ECs in the late-phase inflammation has been distinguished from appropriate time-point by LPS-stimulation $[2,7,8]$ and has complex and abundant changes at the cellular level.

With the advances in systematic tools, the global study of inflammation in cell or organism has become possible and efficient. For example, the mRNA expression profiling was studied in human umbilical vein ECs stimulated with TNF- $\alpha$ [9-11], IL-1 $\beta$ [10], IL-4 [12], Escherichia coli Braun lipoprotein [13], LPS [10, 14], and complement activation product (C5a) [8]. In addition, the global protein expression profiling was also studied in ECs activated with TNF- $\alpha$ [11] and LPS [15]. These studies could provide plenty of data on changes of mRNA or protein caused by different stresses. One main question is how to integrate this information and to explain the complex and important interactions and biological functions. Systems biology, a new discipline of biology, provides a system-level understanding of biological system or response in a cell or organism [16, 17]. Scientists could combine bioinformatics with systematic approaches to provide a systems-wide and in-deep analysis of inflammation [18] and septic shock [19]. Previous studies on inflammatory responses have been focused on human umbilical vein ECs but systems biology studies on major inflammatory animal models such as mice and rats have been relatively rare. One major reason is that the genome and proteome databases of these model animals are relatively incomplete as compared to the human database [20].

In this study, we used primary rat ECs as a model to examine the biological effects of late-phase by LPS-stimulation at the cellular level. This is the first study to use the systems biology approach to explore a global perspective on the complicated systematic changes in LPS-stimulated ECs and to study its biological functions in response to inflammatory stimulation. Moreover, we also developed bioinformatic programs to interpret these huge data and analyze the signifi- cant changes of biological functions or signaling pathways based on the human database in BioCarta, KEGG, and Gene Ontology (GO). A global view of LPS-induced late-phase responses of rat ECs was obtained; these biomarkers and proposed pathways might enable us to develop new diagnosis markers for inflammatory diseases. More importantly, these biomarkers may serve as new drug targets for septic therapeutic studies in the future.

\section{Materials and methods}

\subsection{Cell culture and LPS treatment}

ECs were isolated from thoracic aorta of Sprague-Dawley rats [21] and maintained in the MEM medium (Sigma, St. Louis, MO, USA) supplemented with $10 \%$ fetal calf serum (FCS; PAA, Linz, Austria) and 1\% PSN antibiotics (Gibco, Grand Island, NY, USA). The ECs (passages 5 to 10) were grown to $80-90 \%$ confluence in plastic Petri dishes $(10 \mathrm{~cm})$ and treated with LPS (E. coli 055:B5; Sigma) at 10-1000 $\mu \mathrm{g} /$ $\mathrm{mL}$ for $72 \mathrm{~h}$, and at $100 \mu \mathrm{g} / \mathrm{mL}$ for $0-72 \mathrm{~h}$. Nitrite production in the culture medium was assayed by Griess reaction [22], and cell viability was determined using the alamarBlue assay (BioSource, Camarillo, CA, USA). ECs were treated with LPS $(100 \mu \mathrm{g} / \mathrm{mL})$ for 6 and $72 \mathrm{~h}$ for cDNA microarray and 2-DE experiments, respectively. For the secreted protein array, ECs were cultured in serum-free medium and treated with LPS $(100 \mu \mathrm{g} / \mathrm{mL})$ for $24 \mathrm{~h}$. The mRNA of iNOS and GAPDH were analyzed by isolation of the total RNA via reverse transcription and PCR amplifications of cDNA as described in the Supplementary Material. The control groups of ECs were also cultured in the same medium without LPS.

\subsection{Transcriptomics analysis}

\subsubsection{Total RNA isolation and cDNA preparation}

The ECs were harvested $6 \mathrm{~h}$ after induction by LPS $(100 \mu \mathrm{g} /$ $\mathrm{mL}$ ) and were stored at $-80^{\circ} \mathrm{C}$. The total RNA was isolated using TRIzol (Invitrogen, Carlsbad, CA, USA) and RNeasy kit (Qiagen, Valencia, CA, USA) according to the manufacturers' protocols. RNA concentration was assessed by spectrophotometer at $\mathrm{OD}_{260}$ and RNA integrity was analyzed through the RNA 6000 Nano Lab-Chip kit (Agilent Technologies, Palo Alto, CA, USA) using the Bioanalyzer 2100 (Agilent Technologies). The reverse transcription labeling and hybridization essentially followed the protocol recommended by Agilent Technologies. Briefly, $20 \mu \mathrm{g}$ of each total RNA sample was reverse transcribed into cDNA probes with oligo(dT) primer and labeled nucleotides (Invitrogen). The reaction was carried out in a solution containing $50 \mu \mathrm{M}$ dATP/dGTP/dTTP, $25 \mu \mathrm{M}$ dCTP, $25 \mu \mathrm{M}$ cyanine 3 (Су3)dCTP or cyanine 5 (Cy5)-dCTP and $400 \mathrm{U}$ MMLV reverse transcriptase at $42^{\circ} \mathrm{C}$ for $1 \mathrm{~h}$. The labeling reaction was ter- 
minated by incubating the reaction mixture at $70^{\circ} \mathrm{C}$ for 10 min. The RNA was then degraded by adding RNaseIA $(0.05 \mu \mathrm{g} / \mathrm{mL}$; Agilent Technologies), followed by incubation at room temperature for $30 \mathrm{~min}$. The degraded RNA and the unincorporated nucleotides were removed using a QIAquick PCR Purification Kit (Qiagen).

\subsubsection{Hybridization and data analysis}

Gene expression analysis was performed using a Rat cDNA Microarray kit (Agilent Technologies). Hybridization was carried out in $25 \mu \mathrm{L}$ of a hybridization mixture containing cDNA probes, a labeled orientation marker (Deposition Control SP300; Operon Technologies), and mouse Cot-1 DNA (Invitrogen) at $65^{\circ} \mathrm{C}$ for $17 \mathrm{~h}$. The glass slides were then washed with $0.5 \times \mathrm{SSC}$ and $0.01 \% \mathrm{SDS}$ at room temperature for $5 \mathrm{~min}$, then washed with $0.06 \times \mathrm{SSC}$ also at room temperature for $2 \mathrm{~min}$. After immediately removing the wash buffer by centrifugation, the glass slides were scanned using Agilent DNA Microarray Scanner (Agilent Technologies) containing a $532 \mathrm{~nm}$ laser for Cy3 measurement, and a $633 \mathrm{~nm}$ laser for Cy5 measurement. The image files were processed using the background-subtraction method (Minimum Signal), and dye-normalization (Rank Consistent Filter and LOWESS algorithm) using the Agilent G2566AA Feature Extraction Software Version A.7.1. Data flagged as being of poor quality by the Feature Extraction were manually removed from the analysis using Microsoft Office Excel 2003 (Microsoft Corporation, Redmond, WA). The datasets for each gene were individually queried in the LPS-treatment as compared to the untreated control chip. To select for differentially expressed genes, mRNAs with expression ratios (LPS-treated/untreated control) $>2.0$ and $<0.5$ were selected [23]. There were two independent experiments in the transcriptomic assay.

\subsection{Proteomics analysis}

\subsubsection{Total protein extraction and quantification}

The ECs cultures $\left(1 \times 10^{7}\right.$ cells per dish) were washed twice with cold PBS. To lyse ECs, $200 \mu \mathrm{L}$ of lysis buffer $(50 \mathrm{mM}$ Tris-HCl, $0.1 \mathrm{mM}$ EDTA, $0.1 \mathrm{mM}$ EGTA, $12 \mathrm{mM}$ 2-ME, $1 \mathrm{mM}$ PMSF, $1 \mu \mathrm{g} / \mathrm{mL}$ aprotinin, and $1 \mu \mathrm{g} / \mathrm{mL}$ leupeptin) was added to the culture dish; then the whole cell lysate was scraped and sonicated. The lysate was centrifuged at $12000 \times \mathrm{g}$ for $30 \mathrm{~min}$ at $4^{\circ} \mathrm{C}$. The hydrophilic protein fraction from the supernatant was precipitated using the TCA/acetone method [24]; the cell pellet contained the hydrophobic protein fraction. The protein fractions were directly solublized with rehydration buffer (7 M urea, $2 \mathrm{M}$ thiourea, 4\% w/v CHAPS, 0.5\% IPG ampholine, $65 \mathrm{mM}$ DTE, and 0.002\% bromophenol blue) and were stored at $-80^{\circ} \mathrm{C}$. Protein solutions were diluted 400 -fold by $\mathrm{dd}_{2} \mathrm{O}$ and the concentration was quantified through an $R C D C$ protein assay (Bio-Rad, Hercules, CA, USA).

\subsubsection{2-DE and image analysis}

For each 2-DE analysis, $150 \mu \mathrm{g}$ of protein extract was loaded onto IPG gel strips ( $\mathrm{pH}$ 3-10 nonlinear, 18-cm; Amersham Biosciences, Uppsala, Sweden) and was rehydrated overnight at $30 \mathrm{~V}$ using the IPGphor system (Amersham Biosciences). The first-dimensional IEF was carried out by stepwise voltage increments as follows: $100 \mathrm{~V}$ for $1 \mathrm{~h}, 250 \mathrm{~V}$ for $1 \mathrm{~h}, 500 \mathrm{~V}$ for $1 \mathrm{~h}, 1000 \mathrm{~V}$ for $1 \mathrm{~h}, 4000 \mathrm{~V}$ for $1 \mathrm{~h}$, then $6000 \mathrm{~V}$ for up to $45 \mathrm{kVh}$. Once the IEF was done, the IPG strips were equilibrated for $15 \mathrm{~min}$ in an equilibration solution $(50 \mathrm{mM}$ Tris- $\mathrm{HCl}, \mathrm{pH} 8.8,6 \mathrm{M}$ urea, 2\% w/v SDS, 30\% v/v glycerol, $2 \% \mathrm{w} / \mathrm{v}$ DTE, and $0.002 \%$ bromophenol blue), and were then equilibrated for another $15 \mathrm{~min}$ in a different equilibration solution in which $2.5 \% \mathrm{w} / \mathrm{v}$ iodoacetamide replaced DTE. The 2-D separation was carried out on a 10-18\% acrylamide gradient gel with the PROTEAN II MULTI-CELL (Bio-Rad) at $45 \mathrm{~mA}$ per gel for $5 \mathrm{~h}$. The 2-DE gels were stained with SYPRO Ruby (Molecular Probes, Eugene, OR, USA) and were scanned using the Typhoon 9200 image scanner (Amersham Biosciences). The 2-D gel images were automatically detected and analyzed using the PDQuest software (version 7.1.1; Bio-Rad). The detailed processes and criteria of PDQuest were provided in the Supplementary Material.

\subsubsection{Trypsin digestion and MS analysis}

The in-gel digestion protocol for MALDI-TOF MS analysis has been reported [25]. Briefly, the excised gel pieces were washed three times with $50 \% \mathrm{v} / \mathrm{v} \mathrm{ACN}$ in a $25 \mathrm{mM}$ ammonium bicarbonate destaining buffer $(\mathrm{pH} \mathrm{8.0)}$ for $15 \mathrm{~min}$ at room temperature. Protein digestion was preformed using porcine trypsin (sequencing grade; Promega, Madison, WI, USA). The gel pieces were soaked in $100 \% \mathrm{ACN}$ for $5 \mathrm{~min}$, dried in a lyophilizer for 20-30 min and fully immersed in a $25 \mathrm{mM}$ ammonium bicarbonate buffer ( $\mathrm{pH}$ 8.0) containing $40 \mathrm{ng}$ of trypsin per piece. After incubating for $16 \mathrm{~h}$ at $37^{\circ} \mathrm{C}$, $50 \mu \mathrm{L}$ of the extraction buffer (5\% TFA in $50 \%$ ACN) was added to each gel. The gel pieces were sonicated and spun down. The remaining solution was transferred into another microtube and then concentrated to dryness in a SpeedVac concentrator at $35^{\circ} \mathrm{C}$ for $1.5 \mathrm{~h}$. For MALDI-TOF MS analysis, the sample ( $1 \mu \mathrm{L}$ in $50 \%$ ACN/0.1\% formic acid) was mixed with CHCA ( $1 \mu \mathrm{L}$ of $10 \mathrm{mg} / \mathrm{mL}$ in $60 \% \mathrm{ACN} / 1 \% \mathrm{TFA}$ ) and was applied to each spot. The spots were air-dried at room temperature prior to acquiring mass spectra using a dedicated Q-TOF Ultima ${ }^{\text {TM }}$ MALDI instrument (Micromass, Manchester, UK) with fully automated data directed acquisition using predefined probe motion pattern and peak intensity threshold for switching over from MS survey scan to MS/ MS, and from one MS/MS to another. PMF spectra obtained from each digested protein were compared against SwissProt 49.1 database using the PMF of MASCOT (http:// www.matrixscience.com). Search parameters allowed for oxidation of methionine, carbamidomethylation of cysteine, 
one missed trypsin cleavage, and within 1 Da for peptide mass tolerance. For the peptide sequence searching, the mass spectra were processed and analyzed using the MASCOT MS/MS ion search program using the Swiss-Prot 49.1 database. The search parameters were the same as for PMF search. The mass accuracy was within $50 \mathrm{ppm}$ for the peptide mass tolerance, and within $0.25 \mathrm{Da}$ for fragment mass tolerance. Protein identification was repeated at least once using matched spots from different gels. The detailed processes and parameters of MS have been described in the Supplementary Material.

\subsubsection{Cytokine protein array}

Secreted proteins from ECs were assayed using rat cytokine array (RayBiotech, Norcross, GA, USA) [26]. Serum free culture medium was collected and processed according to the manufacturer's protocol. Briefly, membranes immobilized with capture antibodies were incubated in the conditioned medium. Upon removal of the unbounded cytokines, the membranes were incubated with biotin-conjugated anticytokine antibodies, then with HRP-conjugated streptavidin. Finally, the signals were detected using the ECL system. The ImageMaster 2D platinum (version 5.0; Amersham Biosciences) was used as a densitometer to quantify the intensities of the spot signals.

\subsection{Bioinformatics analysis}

\subsubsection{Biological pathway annotations of differentially expressed genes using Cancer Genome Anatomy Project database}

Differentially expressed genes identified in the cDNA microarray were annotated to specific biological pathways. First, genes (GeneBank IDs) in the rat microarray were correlated to the homologous human UniGene IDs and gene symbols using the NCBI HomoloGene database [27]. For each UniGene ID, we retrieved its biological pathways found in BioCarta (http://www.biocarta.com) and KEGG (http:// www.genome.ad.jp/kegg/pathway.html) through the existing NCI CGAP gene information data (http://cgap.nci. nih.gov/Pathways).

\subsubsection{Functional classification of differentially expressed genes and proteins}

The differentially expressed genes and proteins were ordered into using the BGSSJ (bulk gene search system for Java; http://bgssj.sourceforge.net/) software [28]. BGSSJ is an XML-based Java application that organizes lists of genes or proteins according to GO database for biological interpretation [29]. The application allows easy and interactive queries using various gene or protein identifiers including GenBank accession numbers, UniGene IDs, gene symbols, and SwissProt accession numbers or entry names [30]. It generates a summary page with listings of the frequencies of GO annotations of each functional category within the specified level, and contains separate pages with listings of annotations for each gene in a category. The visualization browser allows users to navigate through the functional category hierarchy, which is displayed in a tree-like structure, and to explore the associated genes or proteins of each category through a userfriendly interface. For our transcriptomic data, the UniGene IDs of the differentially expressed genes were used as the input to BGSSJ with a database option of "NCBI + GO." For proteomic data analysis, the Swiss-Port accession numbers were used as the input to query BGSSJ with a database option of "GOA_UniProt (SWISS_PORT/TrEMBL) + GO." For more exact statistical results on the classification of biological pathways, we also used the web-based ArrayXPath to analyze our data [31].

\section{Results and discussion}

\subsection{Stimulation of ECs by LPS}

Nitrite, a metabolite of NO, is produced via the iNOS enzyme after activation by LPS and/or proinflammatory cytokines and can be used as an indicator of LPS-stimulated responses in ECs. Incubating ECs with LPS $(10-1000 \mu \mathrm{g} / \mathrm{mL})$ for $72 \mathrm{~h}$ resulted in concentration-dependent nitrite accumulation that reached maximum level at $300 \mu \mathrm{g} / \mathrm{mL}$ of LPS, and nitrite level decreased at $1000 \mu \mathrm{g} / \mathrm{mL}$ of LPS (Fig. 1A) most likely due to decreased cell viability (Fig. 1B). As shown in Figure 1C, nitrite level was due to time-dependent accumulation of LPS $(100 \mu \mathrm{g} / \mathrm{mL})$ treatment from 0 to $72 \mathrm{~h}$. At $12 \mathrm{~h}$, nitrite level was already evident and increased progressively with the culture period for up to $72 \mathrm{~h}$. Correspondingly, the mRNA level of iNOS was significantly induced at $6 \mathrm{~h}$ after LPS stimulation, and was sustained up-regulated for up to $24 \mathrm{~h}$ (Fig. 1D). Figure 2 shows the flow chart of systems biology approach by various experiments in this study. We also show the different time-points and the numbers of significantly up- or down-regulated change of mRNAs, cytokines, and proteins by LPS activation in rat ECs.

\subsection{Differential gene expressions and their functional classification for LPS-stimulated ECs}

It was previously shown that most changes of genes in transcriptomics level needed more than $4 \mathrm{~h}$ by C5a stimulation and were identified as late-phase responses in human ECs [8]. We analyzed the late-phase of the transcriptomic level stimulated with LPS for $6 \mathrm{~h}$ by rat cDNA microarray (15 283 gene spots), and obtained 11318 and 12128 reliable gene spots from two independent experiments. Significant changes of mRNA levels in both experiments were shown for 237 genes. Among these genes, we correlated 152 genes (64.1\%) with homologous human UniGene IDs and gene symbols for further functional analysis. We used the BGSSJ 

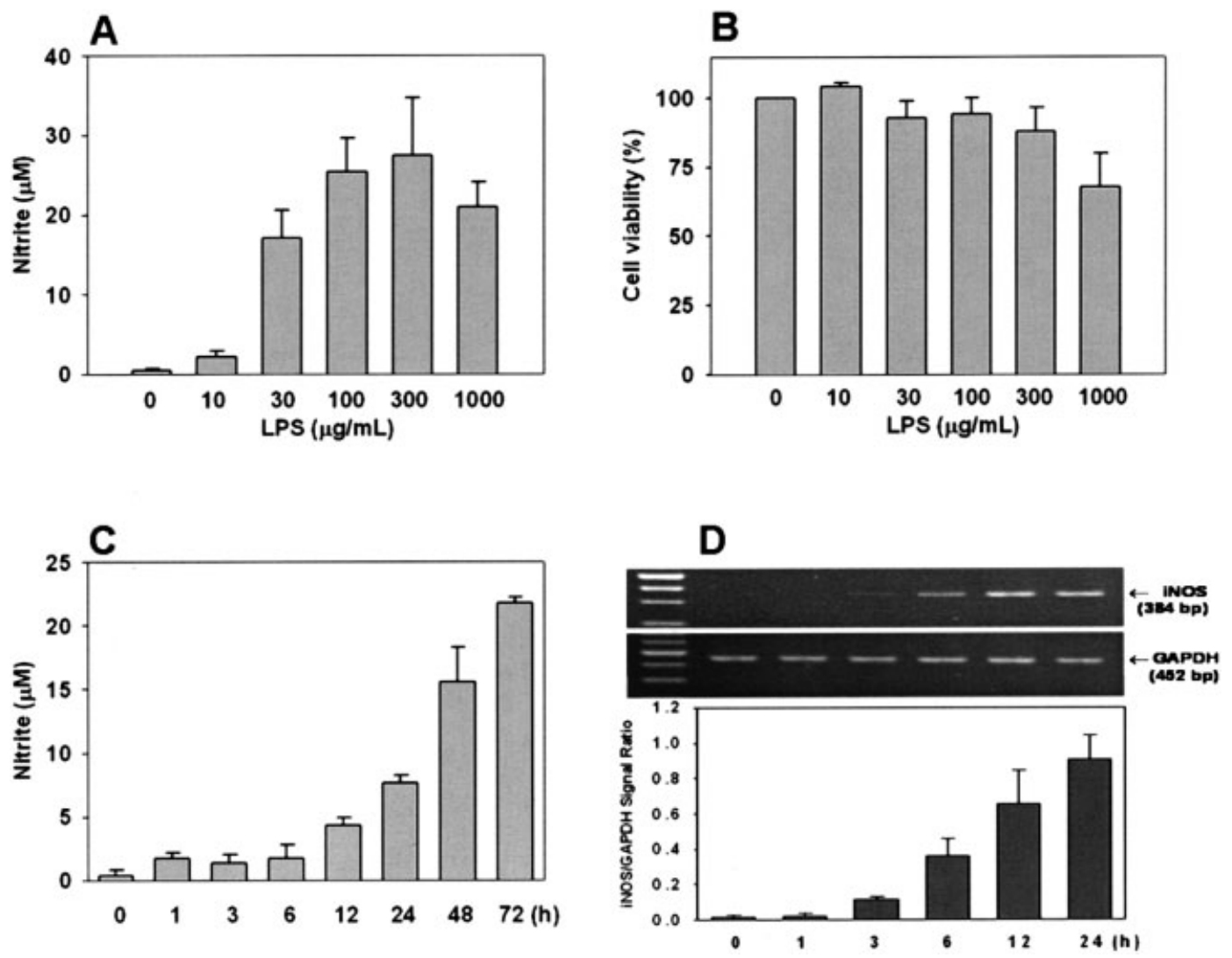

Figure 1. Effects of LPS on iNOS activity and mRNA expression and cytotoxicity in rat ECs. (A) Nitrite accumulation in culture medium was measured by Griess reagent. ECs were stimulated with LPS $(10-1000 \mu \mathrm{g} / \mathrm{mL})$ for $72 \mathrm{~h}$. (B) Cytotoxic effect of LPS $(10-1000 \mu \mathrm{g} / \mathrm{mL}) \mathrm{was}$ treated for $72 \mathrm{~h}$. Cell viability of each treatment was measured by alamarBlue reagent and expressed as a percentage of the control experiment. (C) Time course of nitrite accumulation in culture medium. ECs were stimulated with LPS ( $100 \mu \mathrm{g} / \mathrm{mL}$ ) from 0 to $72 \mathrm{~h}$. (D) Time course of iNOS and GAPDH mRNA expression were measured by RT-PCR. ECs were stimulated with LPS ( $100 \mu \mathrm{g} / \mathrm{mL})$ from 0 to $24 \mathrm{~h}$. These experiments were repeated $3-5$ times with similar results. Results are expressed as the mean \pm SEM.

software to classify and annotate these genes by molecular function based on GO database. Supplementary Table 1 shows that 133 genes could be classified into the following molecular activities, including transcription regulator (7 genes), structure molecule (5 genes), motor (2 genes), enzyme regulator (6 genes), signal transducer (24 genes), transporter (20 genes), antioxidant (1 gene), catalytic (51 genes), binding ( 66 genes), and function unknown ( 6 genes).

Microarray analysis not only assays the changes manifested by specific genes, but it also yields an integrated view of different biological pathways. Using the BioCarta and KEGG database from CGAP, gene information could efficiently classify the differentially expressed mRNAs into specific bioactive pathways. Table 1 shows the functional pathways in which two or more differentially expressed genes have been classified in the given pathway. The BioCarta pathway (Table 1, upper section) identified three different pathways that modulated the responses of innate immunity or inflammation, including "IL-5 signaling pathway," "iNOS-dependent IL-12 pathway in NK cells," and "selective expression of chemokine receptors during T-cell polarization pathway". All these involved genes had upregulated the mRNA expression level, including $I l 1 b, C d 4$, and Cxcr3. On the other hand, "nuclear receptors in lipid metabolism and toxicity" pathway is responsible for controlling the cholesterol and lipid metabolism of some orphan nuclear receptors. In inflammation, the expression of genes involved in lipid uptake and cholesterol efflux are modulated by peroxisome proliferator-activated receptors and liver $\mathrm{X}$ receptors in activated macrophages [32]. Abca1 (ATP-binding cassette A1) acts as a cholesterol efflux pump in the cellular lipid removal pathway. The cytochrome P450 family is responsible for the metabolic activation or inactivation of environmental toxins or xenobiotics, while also changing during the operation in inflammation and infection mechanisms [33]. In our study, all three enzymes, including C $C_{p} 4 b 1, C y p 2 e 1$, and C $>p 7 a 1$, were down-regulated. In the sepsis model, the protein level of CYP2E1 was down-regulated in the rat brain [34]. These changes of cytochrome P450 enzymes will lead to alterations in drug clear- 
Table 1. Functional classification of gene differential expression in LPS-stimulated ECs by BioCarta and KEGG pathway database.

\begin{tabular}{|c|c|c|c|c|c|c|}
\hline Pathways & Gene sym & & & & & a) \\
\hline \multicolumn{7}{|l|}{ Pathways of BioCarta } \\
\hline IL-5 signaling pathway & $/ / 1 b$ & $C d 4$ & & & & 10 \\
\hline iNOS-dependent IL-12 pathway in NK cells & $\mathrm{Cd} 4$ & Cxcr3 & & & & 13 \\
\hline $\begin{array}{l}\text { Nuclear receptors in lipid metabolism } \\
\text { and toxicity }\end{array}$ & Abca1 & Cyp $4 b 1$ & Cyp2e1 & Cyp7a1 & & 34 \\
\hline $\begin{array}{l}\text { Selective expression of chemokine } \\
\text { receptors during } T \text {-cell polarization }\end{array}$ & $C d 4$ & Cxcr3 & & & & 26 \\
\hline \multicolumn{7}{|l|}{ Pathways of KEGG } \\
\hline Pantothenate and CoA biosynthesis & Coasy & Dpyd & Dpys & & & 14 \\
\hline$\beta$-Alanine metabolism & Aldh1a4 & Abat & Dpyd & Dpys & & 25 \\
\hline Phenylalanine metabolism & Aldh3a 1 & Mpo & & & & 18 \\
\hline$\gamma$-Hexachlorocyclohexane degradation & Cyp4f4 & Cyp2a1 & Cyp4b1 & Cyp2e1 & & 36 \\
\hline Carbon fixation & Fbp1 & Fbp2 & & & & 22 \\
\hline Pentose phosphate pathway & Fbp1 & Fbp2 & & & & 23 \\
\hline Tryptophan metabolism & Cyp4f4 & Cyp2a1 & Aldh1a4 & Cyp4b1 & Cyp2e1 & 60 \\
\hline Histidine metabolism & Aldh3a1 & Aldh1a4 & & & & 25 \\
\hline Fatty acid metabolism & Cyp4f4 & Cyp2a1 & Aldh1a4 & Cyp4b1 & Cyp2e1 & 67 \\
\hline Bile acid biosynthesis & Aldh1a4 & Cyp7a1 & & & & 29 \\
\hline Propanoate metabolism & Aldh1a4 & Abat & & & & 30 \\
\hline Fructose and mannose metabolism & Fbp 1 & Fbp2 & & & & 30 \\
\hline Butanoate metabolism & Aldh1a4 & Abat & & & & 31 \\
\hline Glycolysis/gluconeogenesis & Fbp1 & Aldh3a 1 & Fbp2 & Aldh1a4 & & 62 \\
\hline Tyrosine metabolism & $D b h$ & Aldh3a 1 & & & & 34 \\
\hline Prostaglandin and leukotriene metabolism & Tbxas 1 & Mpo & & & & 40 \\
\hline Pyrimidine metabolism & Poli & Dpyd & Dpys & & & 98 \\
\hline Phosphatidylinositol signaling system & Plcg2 & Akt2 & Prkdc & Hunk & & 184 \\
\hline Purine metabolism & Poli & Pde1b & & & & 160 \\
\hline
\end{tabular}

a) Total genes number of this pathway in BioCarta or KEGG database.

ance and toxin activation during inflammatory responses. Low section of Table 1 shows the participated pathways of cellular metabolic processes in LPS-stimulated ECs according to the KEGG database. In an inflammatory condition, the metabolism changes in living organisms or cells, including anabolism and catabolism for small molecules or macromolecular processes such as amino acid, nucleic acid, cofactor, xenobitic, carbohydrate, and lipid. For example, both of fructose-1,6-bisphosphatases (Fbp1 and Fbp2) mRNA levels were up-regulated in LPS-stimulated ECs and classified to four different metabolism pathways. Fructose-1,6-bisphosphatase is a necessary and specific regulatory enzyme to gluconeogenesis. Nonsteroidal anti-inflammatory drugs could interfere with glucose metabolism through glycolysis and oxidative phosphorylation [35].

\subsection{Differential protein expressions for LPS-stimulated ECs}

To study the changes of proteome by 2-DE maps by direct or indirect activation by LPS or LPS-activated molecules, we analyzed the late-phase of LPS activated for $72 \mathrm{~h}$ and this time-point was also analyzed in septic rats [7]. The hydrophilic fractions yielded $64.2 \%$ of the total protein weight, while the hydrophobic fractions were $35.8 \%$. There were more than 1650 individual hydrophilic protein spots (Figs. 3A and B) and 1530 individual hydrophobic protein spots (Figs. 3C and D) detected by the PDQuest software. There were 899 matched spots between LPS-treated and control 2-DE maps of hydrophilic fractions, and 1138 matched spots in the hydrophobic fractions. From these 2-DE maps, we identified 20 protein spots that showed signifi- 


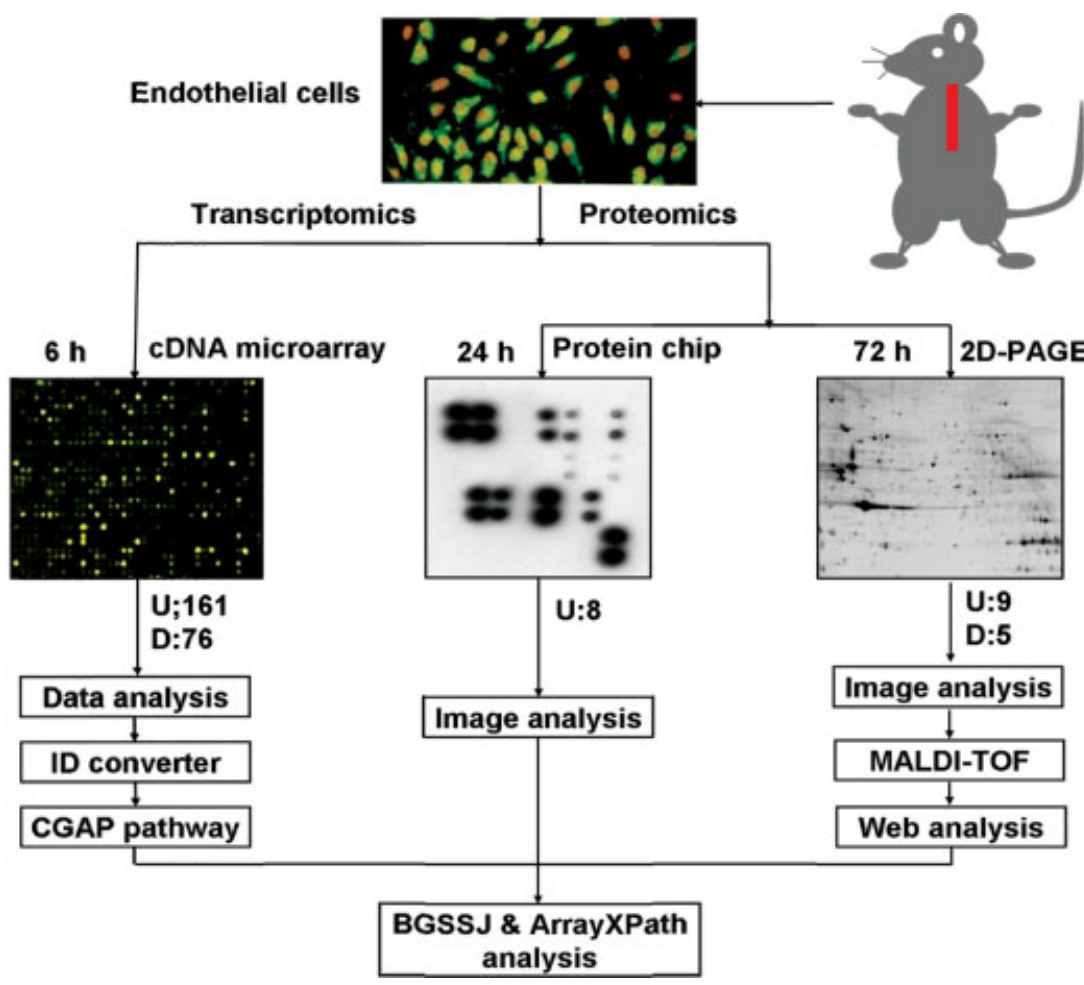

Figure 2. Flow chart of systems biology approach (transcriptomics, proteomics, and bioinformatics) studies of the LPSinduced responses in rat ECs. The numbers of up-regulation $(U)$ and down-regulation (D) of significant changes of mRNAs and proteins are shown under the right side of different systemic approaches.
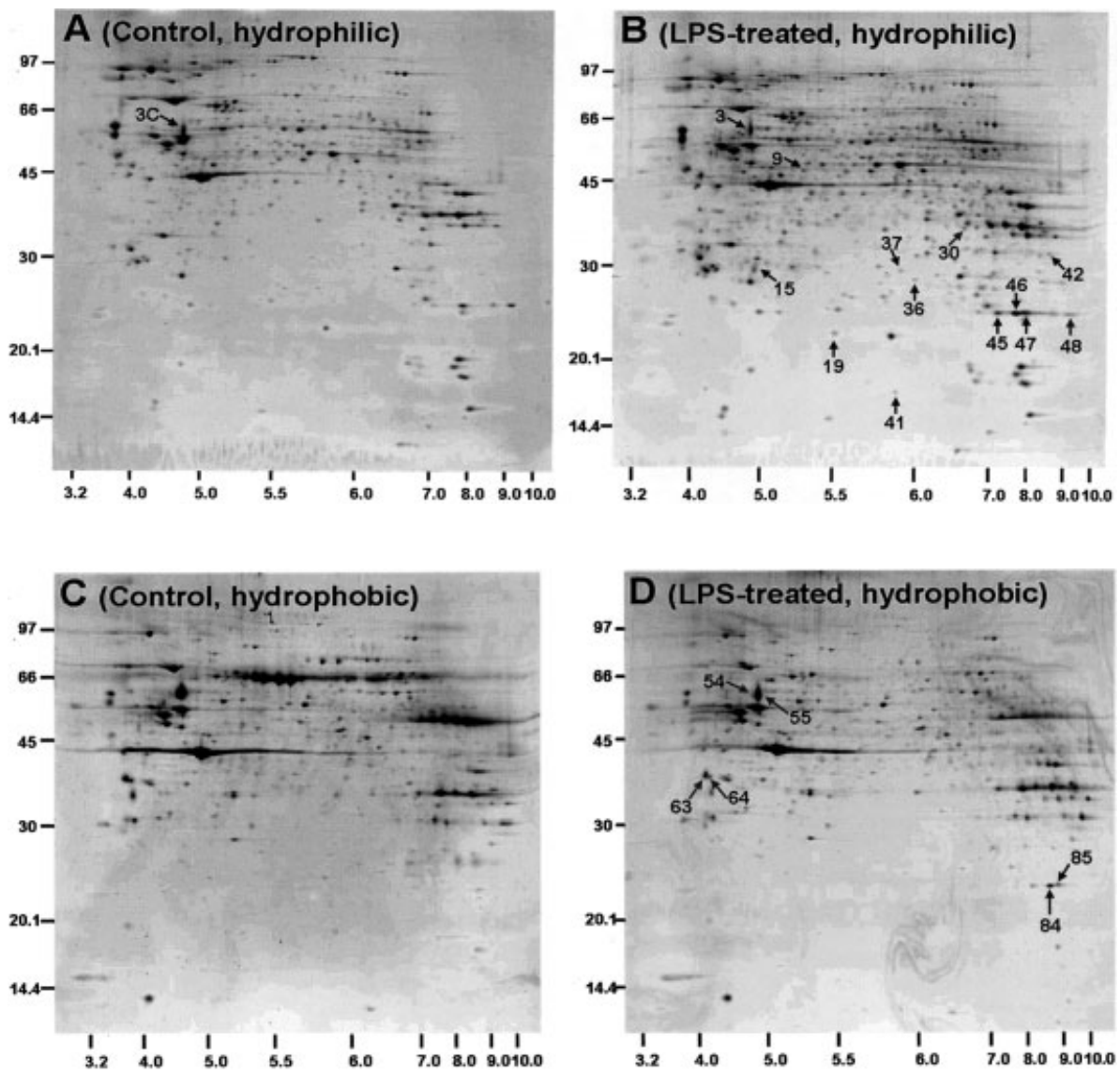

Figure 3. 2-DE maps of identified proteins in hydrophilic fraction (A and $B$ ) and hydrophobic fraction (C and $D)$ from rat ECs. The cells were incubated with vehicle (control; $A$ and $C$ ) or LPS $(100 \mu \mathrm{g} / \mathrm{mL}$ ) (B and $D)$ for $72 \mathrm{~h}$. IPG strips were loaded with $150 \mu \mathrm{g}$ of total proteins for the first dimension focusing. In the second dimension $10-18 \%$ SDSPAGE gels were used. The gels were stained with SYPRO Ruby. Differentially displayed proteins were indicated with arrows. Protein spot numbers are the same as in Figure 4 and Table 2. 
cant changes due to LPS stimulation, all of which contained 14 different proteins. The identified protein spots are described in Table 2, and the detailed PMF and MS/MS data are shown in Supplementary Tables 2 and 3, respectively. The magnified 2-DE maps of these identified spots are shown in Figure 4. After analysis by the PDQuest software, the expression ratio was calculated by dividing the normalized quantity of LPS treatment with the quantity of the control groups from three independent experiments. The identified proteins were classified into seven groups based on cellular location by BGSSJ annotation.

Table 2. Expression changes of proteins by LPS-treatment for $72 \mathrm{~h}$ in rat ECs, and identified by MALDI-Q-TOF MS/MS

\begin{tabular}{|c|c|c|c|c|c|c|c|c|}
\hline $\begin{array}{l}\text { Spot } \\
\text { no. }\end{array}$ & Protein name & $\begin{array}{l}\text { Accession } \\
\text { no. }{ }^{\text {b) }}\end{array}$ & Entry name & $M_{\mathrm{r}} / \mathrm{p} /(\exp )$ & $M_{\mathrm{r}} / \mathrm{p} /(\mathrm{cal})$ & $\begin{array}{l}\text { MS/MS } \\
\text { score }^{\mathrm{cl}}\end{array}$ & $\begin{array}{l}\text { Protein } \\
\text { ratio }^{d)}\end{array}$ & $\begin{array}{l}\text { mRNA } \\
\text { ratio }^{\text {e) }}\end{array}$ \\
\hline \multicolumn{9}{|c|}{ Cytosol proteins } \\
\hline 37 & $\begin{array}{l}\text { Hypoxanthine-guanine phos- } \\
\text { phoribosyltransferase }\end{array}$ & P27605 & HPRT_RAT & $30000 / 6.10$ & $24462 / 6.07$ & 123 & $3.10 \pm 0.87$ & - \\
\hline 45 & Peroxiredoxin 1 & Q63716 & PRDX1_RAT & $26000 / 7.60$ & 22 095/8.27 & 75 & $3.64 \pm 1.23$ & 0.98 \\
\hline 47 & Peroxiredoxin 1 & Q63716 & PRDX1_RAT & $26000 / 8.00$ & 22 095/8.27 & 124 & $1.47 \pm 0.18$ & - \\
\hline 85 & Peroxiredoxin 1 & Q63716 & PRDX1_RAT & $24500 / 7.80$ & 22 095/8.27 & 89 & $2.53 \pm 0.61$ & - \\
\hline 48 & Transgelin & P31232 & TAGL_RAT & $26000 / 9.30$ & $22457 / 8.88$ & 40 & $0.41 \pm 0.04$ & 1.47 \\
\hline \multicolumn{9}{|c|}{ Membrane proteins } \\
\hline 19 & Ferritin heavy chain & P19132 & FRIH_RAT & $23000 / 5.50$ & $20982 / 5.85$ & 77 & $33.3 \pm 17.4$ & \\
\hline 41 & Ferritin light chain & P02793 & FRIL1_RAT & $18000 / 6.10$ & $20662 / 5.98$ & 231 & $3.67 \pm 1.36$ & 1.95 \\
\hline \multicolumn{9}{|c|}{ Cytoskeleton proteins } \\
\hline $3 C$ & Vimentin & P31000 & VIME_RAT & $63800 / 5.00$ & $53569 / 5.06$ & 335 & - & - \\
\hline 3 & Vimentin & P31000 & VIME_RAT & $6600 / 5.000$ & $53569 / 5.06$ & 162 & $0.58 \pm 0.11$ & - \\
\hline 54 & Vimentin & P31000 & VIME_RAT & $63000 / 4.90$ & $53569 / 5.06$ & 261 & $0.46 \pm 0.09$ & - \\
\hline 55 & Vimentin & P31000 & VIME_RAT & $62900 / 5.00$ & $53569 / 5.06$ & 226 & $0.36 \pm 0.08$ & - \\
\hline 63 & Tropomyosin beta chain & P58775 & TPM2_RAT & $44000 / 4.30$ & 32 938/4.63 & 265 & $0.36 \pm 0.19$ & 0.93 \\
\hline 64 & Tropomyosin 1 alpha chain & P04692 & TPM1_RAT & $43000 / 4.30$ & $32675 / 4.71$ & 38 & $0.45 \pm 0.23$ & 1.08 \\
\hline 30 & PDZ and LIM domain protein 1 & P52944 & PDLI1_RAT & $40000 / 7.00$ & $35503 / 6.56$ & 89 & $0.46 \pm 0.20$ & - \\
\hline \multicolumn{9}{|c|}{ ER proteins } \\
\hline 36 & PSA6 & P60901 & PSA6_RAT & $29000 / 6.40$ & $27382 / 6.34$ & 111 & $2.85 \pm 0.69$ & 1.16 \\
\hline \multicolumn{9}{|c|}{ Mitochondrion proteins } \\
\hline 45 & SODM & P07895 & SODM_RAT & $26000 / 7.60$ & $24659 / 8.96$ & 35 & $3.64 \pm 1.23$ & - \\
\hline 46 & SODM & P07895 & SODM_RAT & $26000 / 8.00$ & $24659 / 8.96$ & 134 & $65.9 \pm 22.3$ & - \\
\hline 84 & SODM & P07895 & SODM_RAT & $24000 / 7.70$ & $24659 / 8.96$ & 66 & $12.6 \pm 3.52$ & - \\
\hline 42 & VDAC1 & Q9Z2L0 & VDAC1_RAT & 35 600/8.70 & $30606 / 8.63$ & 65 & $3.49 \pm 1.09$ & 1.11 \\
\hline \multicolumn{9}{|c|}{ Lysosome proteins } \\
\hline 15 & Cathepsin B precursor & P00787 & CATB_RAT & $31000 / 5.10$ & $37446 / 5.36$ & 99 & $2.52 \pm 0.49$ & - \\
\hline \multicolumn{9}{|c|}{ Location unclear } \\
\hline 8 & Guanine deaminase & Q9WTT6 & GUAD_RAT & $55000 / 5.40$ & 50 984/5.56 & 248 & $2.41 \pm 0.26$ & - \\
\hline
\end{tabular}

a) Spot numbers correspond to those in Figures 2 and 3.

b) Accession number according to Swiss-Prot database.

c) MS/MS score was generated by MASCOT: MS/MS Ion Search.

d) The ratio means the protein expression levels between the presence and absence of LPS treatment in ECs and expressed as the mean \pm SEM from three independent 2-DE maps.

e) The ratio means the mRNA expression levels between the presence and absence of LPS treatment in ECs and expressed as the mean of duplicate cDNA microarray assays. 
A

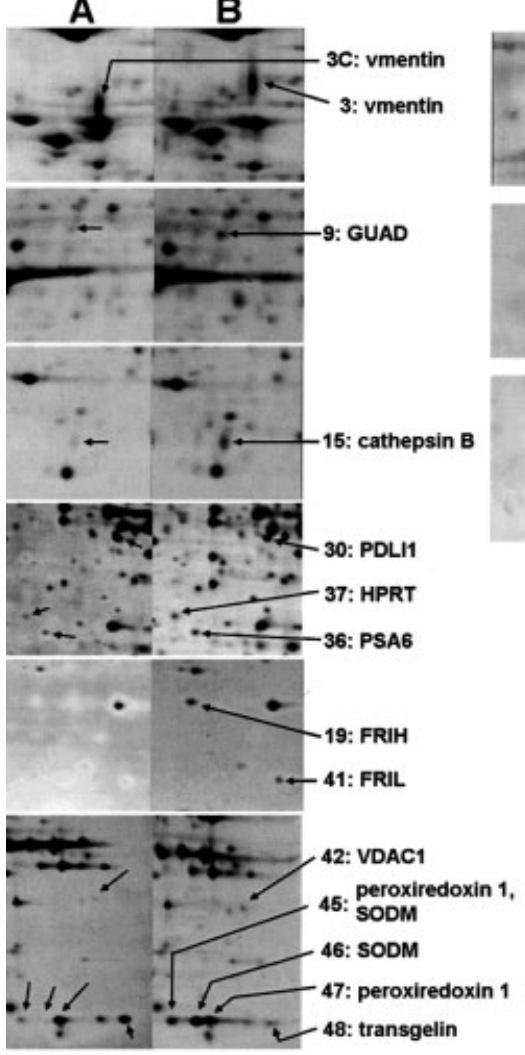

C D
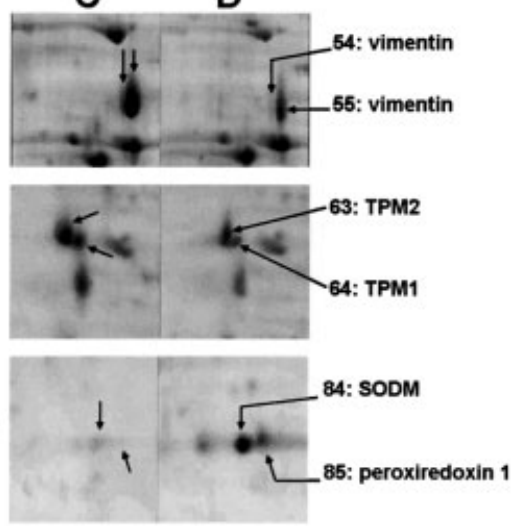

Figure 4. A detailed comparison of the differential protein expression was displayed for the hydrophilic ( $A$ and $B$ ) and hydrophobic fractions $(C$ and $D)$ from rat ECs. The cells were incubated with vehicle (control; $A$ and $C$ ) or LPS-treated (B and D).
Peroxiredoxin is a novel family of antioxidative cytosol proteins. It currently comprises six members in mammals, and is considered to be involved in oxidative stress protection mechanisms [36]. Peroxiredoxin 1 is involved in the redox (reduction-oxidation) regulation of the cell and reduced peroxides with reducing equivalents provided through the thioredoxin system but not from glutaredoxin. In $\mathrm{H}_{2} \mathrm{O}_{2}$ oxidative stress, the oxidation of peroxiredoxin 1 , more acidic $\mathrm{p} I$ value $\left(-\mathrm{Cys}-\mathrm{SO}_{3} \mathrm{H}\right)$ was increased than the basic form (-Cys$\mathrm{SO}_{2} \mathrm{H}$ ) by 2-DE map in rat cardiac myocytes [37] and others cell types. In our 2-DE maps, three spots were identified as peroxiredoxin 1 and the acidic isoforms were shown increased at the protein levels in LPS stimulation. Ferritin has two types of subunits (light and heavy chains), and can store iron in a soluble, nontoxic, readily available form to modulate iron homeostasis. In inflammation, ferritin plays a cytoprotective and antioxidant function to sequestrate iron in porcine endothelium [38]. Ferritin heavy chain (FRIH) and ferritin light chain (FRIL1) were also increased in LPS-stimulated ECs. Moreover, the mRNA expression level of FRIL1 also increased by 1.95 -fold from transcriptomic assay.

During inflammation, modulating the endothelial disposition toward infiltration by leukocytes is important. The permeability of endothelium can be regulated by the integrity of cytoskeletal junctional protein complexes [39]. All of our identified cytoskeletal proteins were down-regulated, including vimentin, tropomyosin $\beta$ chain, tropomyosin $1 \alpha$ chain, and PDZ and LIM domain protein 1. Vimentin is a class III intermediate filament which has important roles in mechanical and biological functions such as cell contractility, migration, stiffness, stiffening, proliferation, and wound healing [40]. Vimentin can be secreted from macrophages by TNF- $\alpha$ trigger and is involved in the bacterial killing and proinflammatory responses [41]. In ER proteins, the proteasome subunit $\alpha$ type 6 (PSA6) was up-regulated in LPS-activated ECs. Proteasome is an abundant multienzyme complex that provides the main pathway toward the degradation of intracellular proteins in eukaryotic cells [42]. Proteasome inhibitors strongly stabilize the protein $I \kappa B \alpha$ to selectively inhibit the activation of NF- $\kappa \mathrm{B}$ in the inflammatory response $[42,43]$. PSA6 might be a significant biomarker or drug target for inflammatory diseases.

On the other hand, Mn-superoxide dismutase (SODM) is responsible for the elimination of cytotoxic molecules of activated oxygen species by catalyzing the dismutation of the superoxide radical to oxygen and hydrogen peroxide. IL-1, TNF- $\alpha$, LPS [44], interferon- $\gamma$ [45], and NO donor [46] are potent activators of SODM in different tissues and cell types. Multiple spots were identified as SODM with significant upregulation. Spot 45 (Fig. 4) increased by about 3.64-fold; however, this spot was identified as both peroxiredoxin 1 and SODM. Spot 46 and spot 84 were identified as SODM and were distinctly inducible by LPS-stimulation. Voltage-dependent anion-selective channel protein 1 (VDAC1) is a pre- 
dominant pore-forming protein in the mitochondrial outer membrane, and is reported to be involved in the maintenance of cellular redox homeostasis [47]. Cathepsin is activated at a low $\mathrm{pH}$ in lysosome vesicles and is involved in cellular metabolism such as peptide biosynthesis and protein degradation. Cathepsin B is involved in the turnover of proteins and participates in intracellular degradation [48]. Indomethacin, an anti-inflammatory drug of cyclooxygenase inhibitor, can significantly reduce elevated cathepsin B activity in septic rats [49]. The cathepsin B inhibitor diminished IL$1 \alpha$, IL-1 $\beta$, and TNF- $\alpha$ production in LPS-stimulated murine macrophages [48]. The inhibition of cathepsin B might be a novel mechanism in anti-inflammatory drug development.

Oxidative stress contributes to ischemia/reperfusion neuronal damage in two consecutive stages: an immediate direct cytotoxic effect, and the subsequent redox-mediated inflammatory responses [50]. SODM is a primary antioxidant defense system against the superoxide radicals, but its product, $\mathrm{H}_{2} \mathrm{O}_{2}$, is also deleterious for cells. Peroxiredoxin 1 also plays an important role in eliminating the peroxide in inflammatory disorder [51]. Dysregulation of the redox cellular imbalance is an important phenomenon for inflammatory response [52]. In our proteomic study, we found a similar redox response in LPS stimulation for $72 \mathrm{~h}$ in ECs. By BGSSJ annotated, we found that VDAC1, SODM, cathepsin $\mathrm{B}$, and peroxiredoxin 1 could play the roles of oxidoreductase activity. PSA6 [42] and cathepsin B [48, 49] played promotional roles in inflammatory responses. However, some proteins had anti-inflammatory or protective characteristics and protein levels of all of these proteins were increased by LPSactivation, e.g., peroxiredoxin 1, SODM, FRIH, and FRIL1.

\subsection{Identification of the secreted proteins of LPS-stimulated ECs by cytokine protein array}

To identify secreted cytokines, ECs were cultured in a serumfree medium to avoid interference from FCS components. The ECs were treated with LPS for $24 \mathrm{~h}$ to generate sufficient cytokines for detection [53] while avoiding the induction of apoptosis due to serum deprivation seen at 48 and $72 \mathrm{~h}$ incubations [54]. All cytokine spots are shown in Figures 5A (control) and 5B (LPS-stimulated). A comparison of the spot volume is shown in Figure 5C. In the control experiment, ECs only secreted TIMP-1 (tissue inhibitor of metalloproteinase 1) and VEGF (vascular endothelial growth factor) to the medium. VEGF is a critical regulator of normal and pathologic angiogenesis processes that induces cell proliferation, promotes cell migration, inhibits apoptosis, and increases permeabilization of blood vessels. In cultured medium, LPSstimulated ECs secreted VEGF about two-fold from the basal level. One proinflammatory cytokine (IL-6) and six chemokines were inducible in LPS-stimulated ECs. IL-6 plays important roles in the regulation of immune response and inflammation. Moreover, the overproduction of IL-6 is involved in the pathology of inflammatory diseases. The
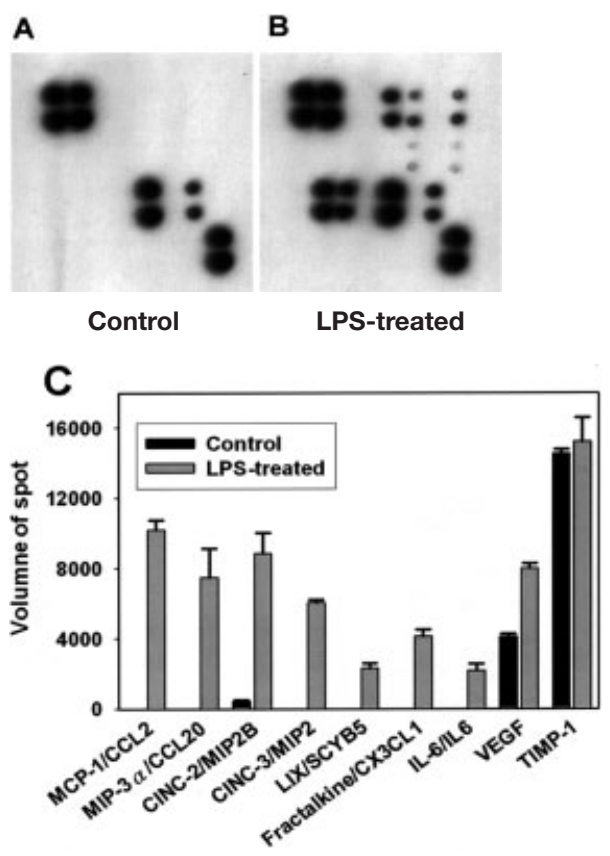

Figure 5. Detection of secreted cytokines from LPS-activated rat ECs by cytokine protein array. Nine cytokines were detected in the serum-free medium by the total of 19 cytokines protein array. Representative membrane protein arrays were hybridized with cultured medium from control (A) and primed the LPS $(100 \mu \mathrm{g} /$ $\mathrm{mL}$ ) (B) after $24 \mathrm{~h}$ incubation. Four spots in the upper left and lower right corners of two spots indicate the positive controls, and four spots were negative controls. (C) Comparison of cytokine signals between control and LPS groups. Results are expressed as the mean \pm SEM of volume from quartic spots in two independent experiments.

production of IL- 6 can be induced by TNF- $\alpha$, IL-1 $\beta$, and LPS in human ECs [55] and is correlated positively with the sepsis or septic shock in the plasma of patients [56]. The six inducible chemokines include the CC family (MCP-1 (Small inducible cytokine A2, CCL2), and MIP-3 $\alpha$ (small inducible cytokine A20, CCL20)), CXC family (CINC-2 (macrophage inflammatory protein-2- $\beta$, MIP2B), CINC-3 (macrophage inflammatory protein 2, MIP2), and LIX (small inducible cytokine B5, SCYB5)), and the unique CX3C family: fractalkine (CX3CL1). The functions of chemokines include leukocyte trafficking, recruiting, and recirculation. Interestingly, in the transcriptomic study, chemokine Ccl21b, and chemokine receptors $\mathrm{Cxcr} 3$ and $\mathrm{C}$ cr10 were all up-regulated in LPS-activated ECs. Chemokines and their receptors are involved in the pathogenesis of systemic inflammatory response resulting from clinical events [57].

\subsection{Functional classification of transcriptomic and proteomic data by bioinformatic analysis}

Aside from using the BioCarta and the KEGG database, we also performed a functional classification analysis of the differentially expressed genes and proteins using BGSSJ in 
accordance with the GO database. This database has an extensive data source and has more cataloged data [29], but the established function in specific pathways are less intact. A total of 152 genes and 22 proteins with human UniGene IDs were annotated by BGSSJ software. There were 153 individual genes or proteins annotated from 174 UniGene IDs, 135 genes or proteins in the cellular component, 134 genes or proteins in the molecular function, and 140 genes or proteins in the biological process. Totally, there were 537 possible classifications from these 153 genes and proteins derived from the BGSSJ analysis. In this analysis, 27 genes and 13 proteins were classified under "response to stimulus" group. Figure 6 shows the Venn diagram for distributions of genes and proteins between "response to stress," "response to external stimulus," and "response to biotic stimulus." The "immune response" was a major response by LPS-activated ECs in previous studies. In our transcriptomics and proteomics data, there were 13 genes and 10 proteins involved in the immunological reaction.

The functional classification of differentially expressed genes and proteins can provide an extensive viewpoint on biological pathway from the BioCarta database, or metabo- lism changes from the KEGG database. This analysis can provide the exact position and detailed data of interesting targets in signaling pathways. Meanwhile, the classification from BGSSJ could give the wide-ranging view and catalog for bulky genes or proteins. The network or pathway changes in activation by LPS showed many extraordinary interrelationships among genes, proteins, small molecules, and cells [58] in the whole organism. Interestingly, some of the pathways or interactions might not have direct association with immune response or inflammation. It means that there were many aspects that could be further studied in LPS-activated ECs.

\subsection{A possible NF- $\mathrm{B}$ signaling modulation and selfprotected responses in LPS-stimulated ECs}

Analyzing the transcriptomic and proteomic data through BGSSJ and ArrayXPath methods not only supply connections between differentially expressed genes or proteins, but also shows the interactions of different signaling pathways and pathophysiologic responses in LPS-activated ECs. In

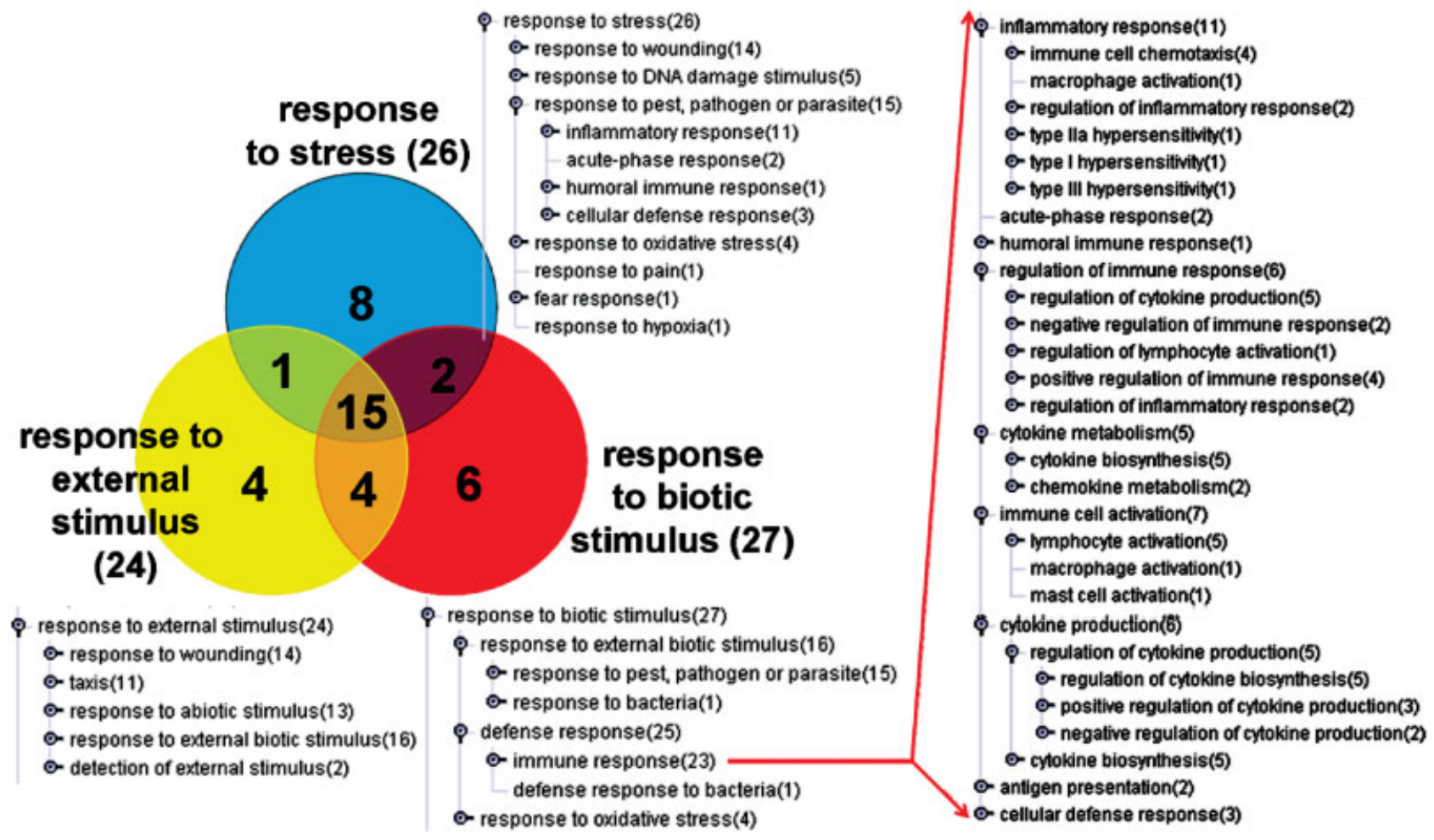

Figure 6. Venn diagram of response to stimulus annotated by BGSSJ software from GO database. A total of 27 genes and 13 proteins were classified to response to stimulus, and divided into three major categories: response to stress (16 genes and 11 proteins), response to external stimulus ( 16 genes and 8 proteins), and response to biotic stimulus ( 16 genes and 12 proteins). The numbers in brackets represent the total amount of genes and proteins in this classification. In immune response, 13 genes and 10 proteins were significantly changed in mRNA and protein levels in LPS-activated ECs. By using the BGSSJ, we could navigate the functional category hierarchy displayed in a tree-like structure and hunt the associated genes or proteins in each category. 
pathway interaction analysis, ArrayXPath offers a less strict criterion which leads to an increased power [31] for mapping the activated biological pathways (based on BioCarta and KEGG databases). We picked up four BioCarta pathways with both $p$-values (pathways scores) and $Q$-values (the significance for any individual pathway) less than 0.05. Figure 7 shows the interaction of four signaling pathways and the modulated activity of NF- $\kappa \mathrm{B}$ signaling through the different products of mRNA (italics) and proteins (nonitalics) in the ArrayXPath analysis. These pathways were also present in our in-house analysis from the BioCarta database. In our study, the mRNA of $I L-1 \beta$ and the proteins of IL- 6 and MCP1 were all up-regulated in rat activated-ECs. This phenomenon was also found in LPS-activated human coronary artery ECs [59]. IL-1 $\beta$, IL-6, and MCP-1 were involved in the inflammatory pathways of "LDL pathway during atherogenesis" and "MSP/RON receptor signaling pathway" through the BioCarta pathways analysis. MSP, a macrophage-stimulating protein, acts through the RON, transmembrane receptor kinase, to play a role in inflammation and in response to tissue injury [60]. IL-1 $\beta$, CD4, and IL-6 were involved and modulated "IL-5 signaling pathway." In inflammatory status, IL-1 $\beta$ and IL- 6 can promote the IL-5 secretion from T-cells and stimulated eosinophil activation. CD4 and chemokine coreceptors (CCR3, CCR5, and CXCR4) were utilized by human immunodeficiency virus type 1 for the entry and infection of mononuclear cells [61], but it is unclear whether these receptors were up-regulated in LPSactivated ECs. Interestingly, the mRNA of the IL-1 receptor antagonist $(I L-1 R N)$, a naturally occurring antagonistic peptide [62], was up-regulated in our LPS-stimulated rat ECs and human ECs [63], but the regulation signaling of IL-1RN was unclear in LPS-stimulated ECs. IL-1RN, IL-1 $\beta$, CD4, IL-6, and MCP-1 could be modulated by NF- $\kappa$ B signaling. NF- $\kappa$ B is a family of dimeric transcription factors composed of members of the Rel family of DNA binding proteins, and is involved in mediating a wide spectrum of cellular responses such as infection, inflammation, and apoptosis [64].

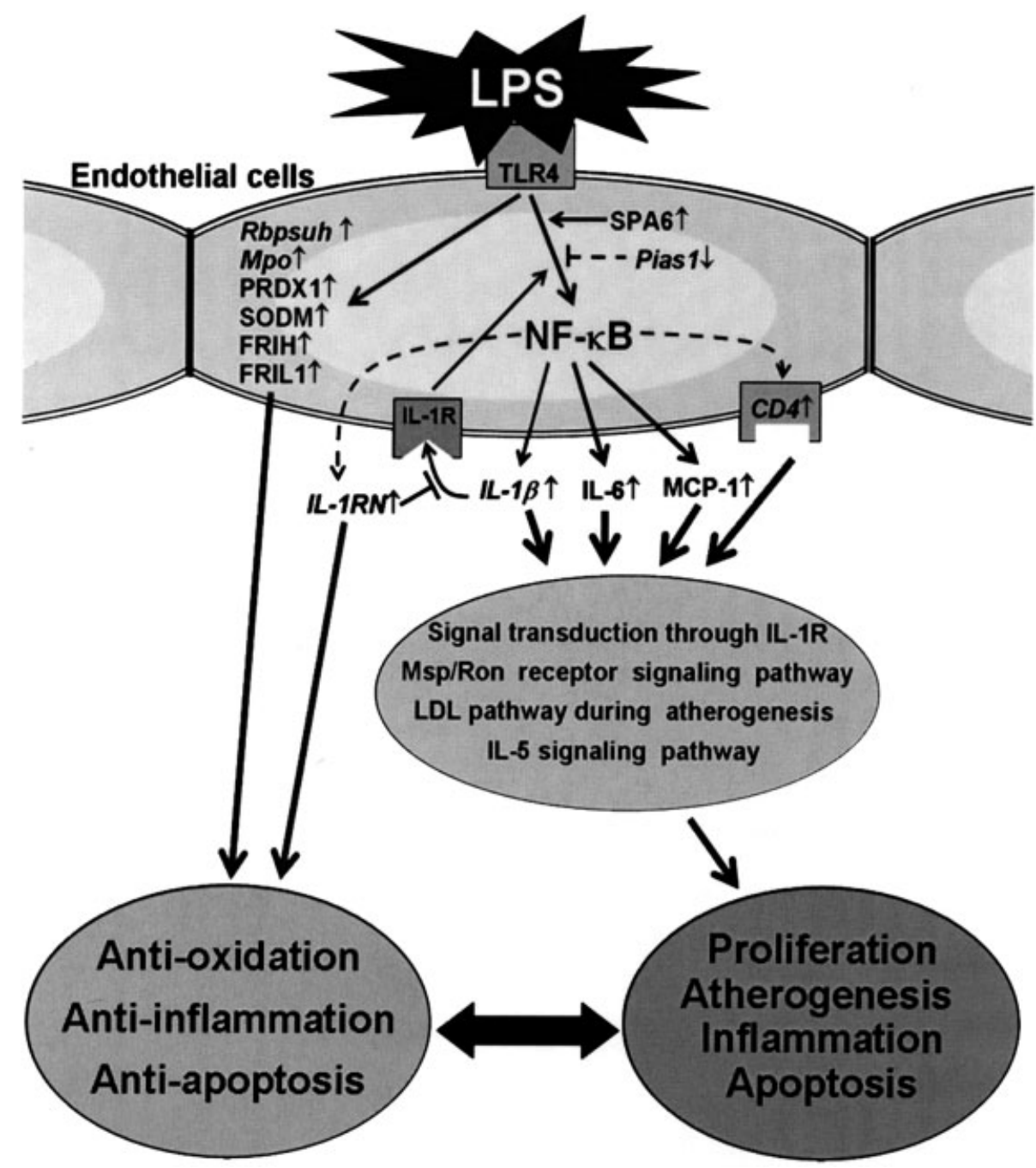

Figure 7. Possible NF- $\mathrm{kB}$ associated responses and selfprotected responses in LPS-stimulated ECs. Binding of LPS to TLR4 results in the activation of transcription factors and regulates the proinflammatory and anti-inflammatory associated gene expressions. The proinflammatory cytokines (IL-1 $\beta$ and IL-6) and chemokine (MCP-1) can be up-regulated by LPS through the activation of the NF$\kappa B$ signaling and transcription regulators (SPA6 and Pias 1) which can also regulate the activity of the NF-KB signaling pathway. Interestingly, the ECs can also up-regulate the mediators of anti-inflammation (IL$1 R N$ ), antiapoptosis (Rbpsun), and antioxidation (Mpo, PRDX1, SODM, FRIH, and FRIL1) to protect themselves against LPS treatment. The direction of arrowheads means the up-regulation or down-regulation of the expression level of mRNA (italics) and protein (non-italics). Dark lines mean that the interaction of mRNA or protein have been verified by other studies, and dashed lines mean that the interactions have not been recognized in ECs. 
From BGSSJ analysis, Pias1 (protein inhibitor of activated STAT1), and Rbpsuh (recombining binding protein suppressor of hairless, RBP-J) were assigned to "transcription regulator activity," and the two gene coding proteins can regulate the activity of the NF- $\mathrm{KB}$ signaling pathway. Pias1 is a member of the PIAS family that could inhibit the transcriptional activity of STAT1 [65] and NF-אB [66] by blocking the DNA binding activity. The activation of NF- $\kappa \mathrm{B}$ signaling by LPS might be increased through down-regulated Pias1 encoded protein expression in ECs. Rbpsuh is a DNA-binding protein that participates in the control of IL- 6 gene expression by overlapping the downstream binding site of NF-кB [67]. The activation of Notch4-Rbpsuh signaling may partially inhibit apoptosis triggered by LPS in human endothelium [68]. The up-regulation of Rbpsuh may play a protective effect in LPS-treated ECs.

Interestingly, the LPS-stimulated ECs could also up-regulate mediators of anti-inflammation $(I L-1 R N)$, antiapoptosis (Rbpsun), and antioxidation (Mpo, PRDX1, SODM, FRIH, and FRIL1) to protect themselves [51]. Combining the transcriptomics and proteomics approaches, and analyzing the data using bioinformatics tools, we derived a possible network for NF-кB signaling pathway, biological pathways, and pathophysiological responses in LPS-treated ECs. The systems biology approaches not only demonstrate the relationship of different genes or proteins, but also facilitate analysis of interactions between physiological or pathophysiological phenomena and biological signal pathways.

\section{Concluding remarks}

The systems biology approach has already been successfully applied to some biological phenomena such as the regulation of sugar metabolic network in yeast [69], and the analysis of differentiation from myeloid leukemia cells to macrophages [70]. Scientists might establish a novel interaction of genes, proteins or signaling pathways, and explain the complexities of biological phenomena or diseases $[19,58]$ based on these systematic analyses. The half-time and turnaround cycle of mRNA and protein in expression level have many differences. It is not possible to evaluate the dynamic changes of biological responses at the same time. In the present study, we used different time-points for direct analysis of the global expression of transcriptome and proteome in latephase of LPS-stimulated rat ECs, and used in-house developed and internet-available bioinformatics programs to compare these bulk experimental data of rat with the established human database. Although our results did not show many concordant changes in the corresponding mRNAs and proteins, the analysis of transcriptomic and proteomic data showed very similar and complementary changes in many pathophysiological responses. Using 2-DE analysis, it is difficult to detect the low expressing proteins, especially for the modulated proteins of signal transduction pathways and metabolism processes. The cDNA or oligonucleotide micro- array is an efficient and systematic approach to study the mRNA changes which regulate the biological responses with low expression on protein levels. Through a proteomic study, we can provide more accurate and correct biomarkers in inflammation studies. By proteomics analysis, we found that PSA6, cathepsin B, IL-6, and some chemokines were increased or induced in LPS-activated ECs. These proteins may play a promotional role in inflammatory responses. Other proteins, such as peroxiredoxin 1, SODM, FRIH, and FRIL1, increased their expression for anti-inflammatory or protective function. These biomarkers could provide comprehensive information for future studies on the characteristics of pathogenesis or selfprotection in ECs faced with external stress. Furthermore, these inflammation-associated mRNAs or proteins might serve as indices to evaluate the anti-inflammatory property in future drug development, for example as proteasome inhibitor and cathepsin B inhibitor [49]. Thus, it is very important to use the systems biology approach to study the global systematic changes in a rat model prior to clinical trials in the therapy of inflammatory diseases. By using the established human database, we can accelerate the efficiency of studies done on other animal models such as rats, or other species with a genome, which are yet to be completeed. In summary, systems biology analysis can integrate many powerful viewpoints to help explain complicated biological phenotypes or diseases which have not been explored in previous studies.

This work was supported by National Science Council of Taiwan (CCMP95-RD-201 and NSC 94-2320-B-077-003) and Academia Sinica, Taiwan (AS-94-TP-B10 and 94C008). Proteomic mass spectrometry and PDQuest software analyses were performed by the Core Facilities for Proteomics Research located at the Institute of Biological Chemsitry, Academia Sinica, supported by a National Science Council grant (NSC 94-3112-B001-010-009-Y) and the Academia Sinica.

\section{References}

[1] Cohen, J., Nature 2002, 420, 885-891.

[2] Hack, C. E., Zeerleder, S., Crit. Care. Med. 2001, 29, S21-S27.

[3] Dauphinee, S. M., Karsan, A., Lab. Invest. 2006, 86, 9-22.

[4] Bannerman, D. D., Goldblum, S. E., Am. J. Physiol. Lung Cell. Mol. Physiol. 2003, 284, L899-L914.

[5] Huang, H., Rose, J. L., Hoyt, D. G., Mol. Pharmacol. 2004, 66, 302-311.

[6] Parrillo, J. E., N. Engl. J. Med. 1993, 328, 1471-1477.

[7] Lee, R. P., Wang, D., Lin, N. T., Chou, Y. W., Chen, H. I., J. Biomed. Sci. 2002, 9, 613-621.

[8] Albrecht, E. A., Chinnaiyan, A. M., Varambally, S., KumarSinha, C. et al., Am. J. Pathol. 2004, 164, 849-859.

[9] Murakami, T., Mataki, C., Nagao, C., Umetani, M. et al., J. Atheroscler. Thromb. 2000, 7, 39-44. 
[10] Zhao, B., Stavchansky, S. A., Bowden, R. A., Bowman, P. D., Am. J. Physiol. Cell Physiol. 2003, 284, C1577-C1583.

[11] Franzen, B., Duvefelt, K., Jonsson, C., Engelhardt, B. et al., Brain Res. Mol. Brain Res. 2003, 115, 130-146.

[12] Lee, Y. W., Eum, S. Y., Chen, K. C., Hennig, B., Toborek, M., Mol. Med. 2004, 10, 19-27.

[13] Neilsen, P. O., Zimmerman, G. A., McIntyre, T. M., J. Immunol. 2001, 167, 5231-5239.

[14] Zhao, B., Bowden, R. A., Stavchansky, S. A., Bowman, P. D., Am. J. Physiol. Cell Physiol. 2001, 281, C1587-C1595.

[15] Karsan, A., Blonder, J., Law, J., Yaquian, E. et al., J. Proteome Res. 2005, 4, 349-357.

[16] Kitano, H., Science 2002, 295, 1662-1664.

[17] Weston, A. D., Hood, L., J. Proteome Res. 2004, 3, 179-196.

[18] Aderem, A., Smith, K. D., Semin. Immunol. 2004, 16, 55-67.

[19] Nguyen, A., Yaffe, M. B., Crit. Care. Med. 2003, 31, S1-S6.

[20] Gibbs, R. A., Weinstock, G. M., Metzker, M. L., Muzny, D. M. et al., Nature 2004, 428, 493-521.

[21] Wang, G. J., Wu, X. C., Chen, C. F., Lin, L. C. et al., J. Pharmacol. Exp. Ther. 1999, 289, 1237-1244.

[22] Green, L. C., Wagner, D. A., Glogowski, J., Skipper, P. L. et al., Anal. Biochem. 1982, 126, 131-138.

[23] Chinnaiyan, A. M., Huber-Lang, M., Kumar-Sinha, C., Barrette, T. R. et al., Am. J. Pathol. 2001, 159, 1199-1209.

[24] Tantipaiboonwong, P., Sinchaikul, S., Sriyam, S., Phutrakul, S., Chen, S. T., Proteomics 2005, 5, 1140-1149.

[25] Jeno, P., Mini, T., Moes, S., Hintermann, E., Horst, M., Anal. Biochem. 1995, 224, 75-82.

[26] Huang, R. P., Huang, R., Fan, Y., Lin, Y., Anal. Biochem. 2001, 294, 55-62.

[27] Wheeler, D. L., Church, D. M., Lash, A. E., Leipe, D. D. et al., Nucleic Acids Res. 2001, 29, 11-16.

[28] Juan, H. F., Huang, H. C., in: Rampal, J. B., Microarrays (2nd Ed.): Applications and Data Analysis. The Human Press Inc., New Jersey, 2001, pp. 401-414.

[29] Ashburner, M., Ball, C. A., Blake, J. A., Botstein, D. et al., Nat. Genet. 2000, 25, 25-29.

[30] Boeckmann, B., Bairoch, A., Apweiler, R., Blatter, M. C. et al., Nucleic Acids Res. 2003, 31, 365-370.

[31] Chung, H. J., Park, C. H., Han, M. R., Lee, S. et al., Nucleic Acids Res. 2005, 33, W621-W626.

[32] Castrillo, A., Tontonoz, P., Annu. Rev. Cell Dev. Biol. 2004, 20, 455-480.

[33] Renton, K. W., Curr. Drug Metab. 2004, 5, 235-243.

[34] Renton, K. W., Nicholson, T. E., J. Pharmacol. Exp. Ther. 2000, 294, 524-530.

[35] Porter, S. N., Howarth, G. S., Butler, R. N., Eur. J. Pharmacol. 2000, 397, 1-9.

[36] Fujii, J., Ikeda, Y., Redox. Rep. 2002, 7, 123-130.

[37] Cullingford, T. E., Wait, R., Clerk, A., Sugden, P. H., J. Mol. Cell. Cardiol. 2006, 40, 157-172.

[38] Balla, G., Jacob, H. S., Balla, J., Rosenberg, M. et al., J. Biol. Chem. 1992, 267, 18148-18153.

[39] Alexander, J. S., Elrod, J. W., J. Anat. 2002, 200, 561-574.

[40] Wang, N., Stamenovic, D., J. Muscle Res. Cell Motil. 2002, $23,535-540$.

[41] Mor-Vaknin, N., Punturieri, A., Sitwala, K., Markovitz, D. M., Nat. Cell Biol. 2003, 5, 59-63.
[42] Palombella, V. J., Rando, O. J., Goldberg, A. L., Maniatis, T., Cell 1994, 78, 773-785.

[43] Griscavage, J. M., Wilk, S., Ignarro, L. J., Proc. Natl. Acad. Sci. USA 1996, 93, 3308-3312.

[44] Visner, G. A., Dougall, W. C., Wilson, J. M., Burr, I. A., Nick, H. S., J. Biol. Chem. 1990, 265, 2856-2864.

[45] Harris, C. A., Derbin, K. S., Hunte-McDonough, B., Krauss, M. R. et al., J. Immunol. 1991, 147, 149-154.

[46] Keller, T., Pleskova, M., McDonald, M. C., Thiemermann, C. et al., Nitric Oxide 2003, 9, 183-193.

[47] Baker, M. A., Lane, D. J., Ly, J. D., De Pinto, V., Lawen, A., J. Biol. Chem. 2004, 279, 4811-4819.

[48] Schotte, P., Schauvliege, R., Janssens, S., Beyaert, R., J. Biol. Chem. 2001, 276, 21153-21157.

[49] Hummel, R. P., III, Warner, B. W., James, J. H., Hasselgren, P. O., Fischer, J. E., J. Surg. Res. 1988, 45, 140-144.

[50] Zhang, N., Komine-Kobayashi, M., Tanaka, R., Liu, M. et al., Stroke 2005, 36, 2220-2225.

[51] Rivollier, A., Perrin-Cocon, L., Luche, S., Diemer, H. et al., Mol. Cell. Proteomics 2006, 5, 726-736.

[52] Macdonald, J., Galley, H. F., Webster, N. R., Br. J. Anaesth. 2003, 90, 221-232.

[53] Bobrowski, W. F., McDuffie, J. E., Sobocinski, G., Chupka, J. et al., Cytokine 2005, 32, 194-198.

[54] Hogg, N., Browning, J., Howard, T., Winterford, C. et al., Endothelium 1999, 7, 35-49.

[55] Galley, H. F., Nelson, S. J., Dhillon, J., Dubbels, A. M., Webster, N. R., Crit. Care. Med. 1999, 27, 908-912.

[56] Souter, P. J., Thomas, S., Hubbard, A. R., Poole, S. et al., Crit. Care. Med. 2001, 29, 134-139.

[57] Puneet, P., Moochhala, S., Bhatia, M., Am. J. Physiol. Lung Cell. Mol. Physiol. 2005, 288, L3-L15.

[58] Calvano, S. E., Xiao, W., Richards, D. R., Felciano, R. M. et al., Nature 2005, 437, 1032-1037.

[59] Zeuke, S., Ulmer, A. J., Kusumoto, S., Katus, H. A., Heine, H., Cardiovasc. Res. 2002, 56, 126-134.

[60] Wang, M. H., Zhou, Y. Q., Chen, Y. Q., Scand. J. Immunol. $2002,56,545-553$.

[61] Chi, D., Henry, J., Kelley, J., Thorpe, R. et al., Endothelium 2000, 7, 223-242.

[62] Eisenberg, S. P., Evans, R. J., Arend, W. P., Verderber, E. et al., Nature 1990, 343, 341-346.

[63] Dewberry, R., Holden, H., Crossman, D., Francis, S., Arterioscler. Thromb. Vasc. Biol. 2000, 20, 2394-2400.

[64] Ghosh, S., May, M. J., Kopp, E. B., Annu. Rev. Immunol. $1998,16,225-260$

[65] Liu, B., Liao, J., Rao, X., Kushner, S. A. et al., Proc. Natl. Acad. Sci USA 1998, 95, 10626-10631.

[66] Liu, B., Yang, R., Wong, K. A., Getman, C. et al., Mol. Cell. Biol. 2005, 25, 1113-1123.

[67] Vales, L. D., Friedl, E. M., J. Biol. Chem. 2002, 277, 4243842446.

[68] MacKenzie, F., Duriez, P., Wong, F., Noseda, M., Karsan, A., J. Biol. Chem. 2004, 279, 11657-11663.

[69] Ideker, T., Thorsson, V., Ranish, J. A., Christmas, R. et al., Science 2001, 292, 929-934.

[70] Juan, H. F., Lin, J. Y., Chang, W. H., Wu, C. Y. et al., Electrophoresis 2002, 23, 2490-2504. 